\title{
S-carboxymethylcysteine inhibits the attachment of Streptococcus pneumoniae to human pharyngeal epithelial cells
}

\author{
Gulcin Cakan ${ }^{\mathrm{a}, 1}$, Mustafa Turkoz ${ }^{\mathrm{a}, 1}$, Tolga Turan ${ }^{\mathrm{a}}$, Kamruddin Ahmed $^{\mathrm{a}, *}$, Tsuyoshi Nagatake $^{\mathrm{b}}$ \\ ${ }^{a}$ Department of Molecular Biology and Genetics, Bilkent University, Ankara 06533, Turkey \\ ${ }^{\mathrm{b}}$ Department of Internal Medicine, Institute of Tropical Medicine, Nagasaki University, Nagasaki, Japan
}

Received 4 December 2002; received in revised form 30 January 2003; accepted 10 February 2003

\begin{abstract}
Streptococcus pneumoniae causes respiratory and other invasive infections. Increased resistance of this bacterium to antibiotics necessitates new approaches to the treatment of infections. Attachment of bacteria to human pharyngeal epithelial cells is the initial step in the pathogenesis of infection and $S$-carboxymethylcysteine $(S$-CMC) can modulate the attachment of Moraxella catarrhalis and nontypable Haemophilus influenzae to epithelial cells. Unlike these two, S. pneumoniae is gram-positive and has a well-defined capsule. Here we examined the effects of $S$-CMC on the attachment and detachment of $S$. pneumoniae to human pharyngeal epithelial cells in vitro. Treatment of these cells with $S$-CMC significantly reduced the number of attached $S$. pneumoniae. $S$-CMC also resulted in a significant increase in the detachment of already attached $S$. pneumoniae to epithelial cells. In addition, treatment of $S$. pneumoniae with $S$-CMC significantly reduced their ability to attach to epithelial cells, but not the number of viable bacteria. Our study shows that $S$-CMC modulates the attachment of $S$. pneumoniae to human pharyngeal epithelial cells by acting both on cells and bacteria.
\end{abstract}

(C) 2003 Elsevier Science Ltd. All rights reserved.

Keywords: Respiratory infection; Bacterial attachment; Mucosa; Epithelial cells; Bacterial adherence

\section{Introduction}

Attachment of bacteria to host epithelial cells is the first step in the pathogenesis of bacterial infections. Streptococcus pneumoniae is one of the major groups of bacteria that can cause various invasive and noninvasive infections. Most of these infections are preceded by colonization of the pharynx by $S$. pneumoniae. Then either the bacteria invade the lower respiratory tract causing bronchopneumonia and subsequently invade the blood stream or remain localized and cause infection of the mucosal tissue. In severe cases, the colonized bacterium may invade the upper airways directly to cause meningitis. Therefore, inhibition of bacterial colonization in the pharyngeal area seems to be a useful strategy to prevent infections. This may be achieved by either systemic or local use of antiattachment agents such as antibodies, receptor analogues or

\footnotetext{
* Corresponding author. Tel.: +90-312-2902408; fax: +90-3122665097.

E-mail address: ahmed@fen.bilkent.edu.tr (K. Ahmed).

1 G.C. and M.T. contributed equally in this work.
}

other agents such as xylitol [1], $\mathrm{N}$-acetylcysteine [2] and $S$-carboxymethylcysteine ( $S$-CMC). Among these, $S$-CMC is perhaps the most promising agent since previous studies have shown that it significantly reduced the number of episodes of acute exacerbations of respiratory infections when administered systemically [3]. Previous studies have also demonstrated that $S$-CMC acts both in vitro and in vivo, by rendering pharyngeal epithelial cells capable of inhibiting the adhesion of $M$. catarrhalis and nontypable Hemophilus influenzae (NTHI) [4,5].

$S$-CMC is a mucolytic agent and has been used in the treatment of different respiratory diseases characterized by abnormal mucus secretion $[4,5]$. It is also effective for the treatment of otitis media with effusion in children [6]. The precise mode of action of $S$-CMC is unknown; it corrects the intracellular abnormalities of glycoprotein synthesis and normalizes the secretory function of the mucosal epithelium [7].

To our knowledge, the effects of $S$-CMC on grampositive bacteria and bacteria with a well-defined capsule have not been investigated. These features apply to $S$. pneumoniae, which is also one of the most significant 
pathogens known to cause respiratory tract infections. Furthermore, the increased number of antibiotic-resistant $S$. pneumoniae makes treatment of infections caused by such bacteria difficult to control with commonly used antibiotics. The present study was designed to examine the effects of $S$-CMC on the attachment of $S$. pneumoniae to pharyngeal epithelial cells. Our results indicated that $S$-CMC could modulate the attachment of $S$. pneumoniae to human pharyngeal epithelial cells by acting both on the cells and bacteria. The results suggest that this drug may be potentially useful for the prevention of $S$. pneumoniae infections.

\section{Results}

\subsection{S-CMC inhibits attachment of S. pneumoniae to epithelial cells}

Taking all the data of controls into consideration, the mean number of S. pneumoniae strain SP-95-19 attached per epithelial cells was $17.0 \pm 8.1$. The attachment of this strain to epithelial cells significantly decreased following treatment of the cells with $S$-CMC at a concentration of 100, 10, 1 or $0.1 \mu \mathrm{g} / \mathrm{ml}(P<0.05$, Table 1$)$. However, at 0.01 and $0.001 \mu \mathrm{g} / \mathrm{ml}, S$-CMC had no effect on attachment. Treatment of pharyngeal epithelial cells with $S$-CMC at a concentration of $0.1 \mu \mathrm{g} / \mathrm{ml}$ resulted in a significant $(P<$ $0.001)$ decrease in the attachment of the other three strains of S. pneumoniae (SP-95-27, SP-96-29 and SP-95-36) to $33.9 \pm 0.8 \%$ of the control.

\subsection{S-CMC enhances detachment of bacteria from epithelial cells}

Following the completion of the attachment assay, epithelial cells with the attached S. pneumoniae strain SP95-19 were treated with $100,10,1$ or $0.1 \mu \mathrm{g} / \mathrm{ml} S$-CMC. This resulted in a significant decrease in the number of attached bacteria (Table 2). However, no such decrease was

Table 1

Effects of $S$-carboxymethylcysteine treatment of pharyngeal epithelial cells on the attachment of S. pneumoniae strain SP-95-19

\begin{tabular}{lllll}
\hline Control & $\begin{array}{l}\text { Attachment } \\
S \text {-CMC }(\mu \mathrm{g} / \mathrm{ml})\end{array}$ & $\begin{array}{l}\text { Decrease in } \\
\text { mean attach } \\
\text { ment }(\%)\end{array}$ & $P$ value & $\begin{array}{l}\text { Number of } \\
\text { experiments }\end{array}$ \\
\hline $17.8 \pm 10.1$ & $5.1 \pm 2.6(100)$ & 71.3 & $<0.05$ & 6 \\
$20.2 \pm 10.2$ & $6.9 \pm 3.4(10)$ & 65.8 & $<0.05$ & 6 \\
$19.0 \pm 9.9$ & $8.3 \pm 4.6(1)$ & 56.3 & $<0.05$ & 7 \\
$19.0 \pm 9.9$ & $8.4 \pm 3.8(0.1)$ & 55.8 & $<0.05$ & 7 \\
$11.3 \pm 1.9$ & $8.6 \pm 5.8(0.01)$ & 23.9 & NS & 4 \\
$15.0 \pm 5.5$ & $12.7 \pm 4.1(0.001)$ & 16.7 & NS & 3
\end{tabular}

Attachment is expressed as number of bacteria attached per pharyngeal epithelial cell. Each experiment was performed in duplicate. For a given concentration of $S$-CMC treatment, experiments were done in separate days. $P$ values are for comparisons with the control. NS, not significant.
Table 2

Effects of $S$-carboxymethylcysteine on detachment of $S$. pneumoniae strain SP-95-19 adherent to human pharyngeal epithelial cells

\begin{tabular}{lclll}
\hline Control & $\begin{array}{l}\text { Detachment } S \\
\text {-CMC }(\mu \mathrm{g} / \mathrm{ml})\end{array}$ & $\begin{array}{l}\text { Decrease in } \\
\text { mean detach } \\
\text { ment }(\%)\end{array}$ & $P$ value & $\begin{array}{l}\text { Number of } \\
\text { experiments }\end{array}$ \\
\hline $8.9 \pm 2.7$ & $3.4 \pm 3.1(100)$ & 69.7 & $<0.005$ & 5 \\
$8.9 \pm 2.4$ & $2.6 \pm 1.7(10)$ & 70.8 & $<0.005$ & 5 \\
$8.9 \pm 2.4$ & $2.7 \pm 1.5(1)$ & 69.7 & $<0.005$ & 5 \\
$8.2 \pm 2.9$ & $2.5 \pm 1.4(0.1)$ & 69.5 & $<0.05$ & 3 \\
$10.4 \pm 1.0$ & $11.7 \pm 1.7(0.01)$ & ND & NS & 3 \\
$10.4 \pm 1.0$ & $9.4 \pm 1.0(0.001)$ & 9.6 & NS & 3 \\
\hline
\end{tabular}

Detachment is expressed as number of attached bacteria per pharyngeal epithelial cell after detachment assay. Each experiment was performed in duplicate. For a given concentration of $S$-CMC treatment, experiments were done in separate days. $P$ values are for comparisons with the control. ND, no decrease; NS, not significant.

noted when cells were treated with 0.01 and $0.001 \mu \mathrm{g} / \mathrm{ml} S$ CMC (Table 2).

The detachment assay also showed a significant $(P<$ $0.05)$ decrease in the proportion of the other three strains of S. pneumoniae (SP-95-27, SP-96-29 and SP-95-36) to $44.3 \pm 17.3 \%$ of the control, when pharyngeal epithelial cells with the attached bacteria were treated with $0.1 \mu \mathrm{g} / \mathrm{ml}$ $S$-CMC.

\subsection{Effects of S-CMC treatment of bacteria on attachment to epithelial cells}

$S$-CMC treatment did not change the cell wall or Gram staining pattern of $S$. pneumoniae. Treatment of $S$. pneumoniae strain SP-95-19 with 10 or $1 \mu \mathrm{g} / \mathrm{ml} S$-CMC significantly decreased the number of bacteria attached to epithelial cells (Table 3). However, at concentrations of 0.1 and $0.01 \mu \mathrm{g} / \mathrm{ml}, S$-CMC had no significant effect on the number of attached bacteria.

Treatment of the other three strains of $S$. pneumoniae (SP-95-27, SP-96-29 and SP-95-36) with $10 \mu \mathrm{g} / \mathrm{ml}$ of

Table 3

Effects of $S$-carboxymethylcysteine treatment of $S$. pneumoniae strain SP95-19 on their attachment to human pharyngeal epithelial cells

\begin{tabular}{llll}
\hline $\begin{array}{l}S \text {-CMC concen } \\
\text { tration }(\mu \mathrm{g} / \mathrm{ml})\end{array}$ & Attachment & $\begin{array}{l}\text { Decrease in mean } \\
\text { attachment }(\%)\end{array}$ & $P$ value \\
\hline 0 (Control) & $31.6 \pm 8.0$ & & \\
10 & $16.8 \pm 11.2$ & $46.8 \%$ & $<0.01$ \\
1 & $19.7 \pm 8.5$ & $37.7 \%$ & $<0.001$ \\
0.1 & $21.1 \pm 8.6$ & $33.2 \%$ & $\mathrm{NS}$ \\
0.01 & $37.8 \pm 11.4$ & $\mathrm{ND}$ & $\mathrm{NS}$ \\
\hline
\end{tabular}

Attachment is expressed as number of bacteria attached per pharyngeal epithelial cell. A total of four experiments were performed at each concentration. For a given concentration of $S$-CMC treatment, experiments were done in separate days. $P$ values are for comparisons with the control. NS, not significant; ND, no decrease. 
$S$-CMC resulted in a significant $(p<0.001)$ decrease in the number of attached bacteria to $37.1 \pm 1.7 \%$ of the control. However, the effect was variable when these strains when treated with $1 \mu \mathrm{g} / \mathrm{ml}$ of $S$-CMC. In strain SP-95-27, SP-9629 and SP-95-36, the attachment decreased to $34.4 \%, 14.6 \%$ and $1.1 \%$ of the control, respectively.

\subsection{S-CMC has no effect on viability of bacteria}

Treatment of S. pneumoniae with S-CMC did not affect the viability of bacteria relative to the control (data not shown).

\section{Discussion}

Although the pneumococcal polysaccharide vaccine has been licensed for the last 20 years in the US and UK, the effectiveness of this vaccine in preventing infections in the vulnerable population is not satisfactory [8]. In addition, the worldwide spread of penicillin-resistant $S$. pneumoniae emphasizes the need for new approaches to prevent such bacterial infections [9]. The use of a drug that can block $S$. pneumoniae attachment to epithelial cells represents a new approach for the prevention and treatment of infections caused by this microbe. In the present study, we showed that $S$-CMC at a concentration achievable in the sputum [4] inhibited the attachment of $S$. pneumoniae to human pharyngeal epithelial cells in vitro as well the detachment of the already attached $S$. pneumoniae from human pharyngeal epithelial cells. The mechanism by which $S$-CMC prevents the bacterial attachment is not known at present. Since the suppression of attachment was also noted for M. catarrhalis and NTHI, it is likely that S-CMC acts on a common receptor, or it masks the receptor. Compared to M. catarrhalis and NTHI [4,5], significant inhibition of $S$. pneumoniae attachment was achieved when epithelial cells were treated with low concentrations of $S$-CMC. Moreover, detachment was also observed at relatively low concentration of $S$-CMC compared with that of NTHI [5].

A two-step molecular model has been proposed for the attachment of $S$. pneumoniae to eucaryotic cells [10] where the initial encounter between pneumococci and naive host cells is mediated by resting eucaryotic cell receptors. With increasing numbers of bacteria, the induced inflammatory response upregulates new eucaryotic cell receptors that promote addition bacterial attachment. $S$-CMC appears to have an anti-inflammatory function, probably through its effect on sialomucin synthesis and subsequent kinin inhibition [7]. It is still not clear whether $S$-CMC can prevent such receptor upregulation by downregulating the inflammatory response.

The most important and interesting finding of the present study was the significant decrease in the attachment following treatment of $S$. pneumoniae with $S$-CMC. Certainly this effect was not due to any bactericidal effect of $S$-CMC because our quantitative culture assays showed that $S$-CMC had no effect on viable bacterial counts. In addition the reduction in the attachment correlated well with the dose of $S$-CMC used for the treatment of $S$. pneumoniae. Our previous studies showed that $S$-CMC could not reduce the attachment of $M$. catarrhalis and NTHI to epithelial cells $[4,5]$. The mechanism of $S$-CMC-induced attenuation of $S$. pneumoniae attachment to human pharyngeal epithelial cells certainly deserves further investigation. We previously showed that $S$-CMC could remove carbohydrate from the cell surface [4]. Others have shown that $N$-acetylL-cysteine, another mucolytic agent, successfully removed the capsule of $S$. pneumoniae in transformation experiments [11]. It is possible that the effect of $S$-CMC noted in the present study was also due to the same mechanism. $S$. pneumoniae has a well-established capsule in contrast to NTHI and $M$. catarrhalis. In this regard, previous studies showed that the adherence of noncapsulated forms of $S$. pneumoniae to bronchial epithelial cells was stronger than the capsulated parent strain [12]. On the other hand, several proteins on $S$. pneumoniae cell wall, such as choline binding proteins $[13,14]$ and peptide permeases [10] have been reported to act as adhesins assisting bacterial attachment to human bronchial epithelial cell line. It should be noted however, that cultured cells may express aberrant receptor(s) because cell lines are prepared from cancer tissues or modified by virus infection. It may be possible that due to this noncapsulated $S$. pneumoniae attach more to cultured cells than capsulated one. Since we are using cells directly scraped from human pharynx, therefore, the utilization of receptors by $S$. pneumoniae for attachment is possibly different from cultured cells. Recently, Dagan and colleagues [15] reported a significant decrease of nasopharyngeal carriage of S. pneumoniae after administration of a 9valent pneumococcal conjugate vaccine. It seems that anticapsular antibodies prevented attachment and decrease of colonization occurred. Therefore it is possible that the bacterial capsule could play a role in the attachment to human pharyngeal epithelial cells. Studies are currently being conducted in our laboratories to determine the role of $S$. pneumoniae capsule in their attachment to human pharyngeal epithelial cells and the mechanism of action of $S$-CMC on the capsule of $S$. pneumoniae.

The major pathogens causing respiratory infections are $S$. pneumoniae, NTHI and M. catarrhalis [16]. It became clear with this study that $S$-CMC reduces the number of episodes of acute exacerbation of respiratory infections by rendering pharyngeal epithelial cells capable of inhibiting the attachment of all these major pathogens.

\section{Materials and methods}

\subsection{Bacteria}

The following strains of $S$. pneumoniae were used in this study: strain SP-95-27 of serotype 9V isolated from 
post-mortem lung tissue; strain SP-95-19 of serotype 19F isolated from the sputum of a patient with respiratory infection; strain SP-96-29 of serotype 6B isolated from secretion that accumulated inside the endotracheal tube of an unconscious patient; and strain SP-95-36 of serotype 14 isolated from throat swab of a patient. Strain SP-95-19 was used in most experiments unless otherwise stated. All strains were stocked in MuellerHinton broth (Merck KgaA, Darmstadt, Germany) containing 5\% defibrinated rabbit blood and kept at $-20{ }^{\circ} \mathrm{C}$ until use. For attachment studies, assay bacteria were cultured overnight on Brain Heart Infusion agar (Merck KgaA, Darmstadt, Germany) containing 7\% defibrinated rabbit blood at $37{ }^{\circ} \mathrm{C}$ in $5 \% \mathrm{CO}_{2}$ incubator, then the colony was transferred to Todd-Hewitt broth (Difco Laboratories, Detroit, MI, USA) containing 0.5\% yeast extract and cultured in an incubator under constant shaking at $37^{\circ} \mathrm{C}$ for $6 \mathrm{~h}$. This yielded a bacterial density of $5 \times 10^{7} \mathrm{cfu} / \mathrm{ml}$ of $S$. pneumoniae. For each experiment this was confirmed by quantitative culture. The bacteria were washed once in phosphate buffered saline (PBS), $\mathrm{pH} 7.2$, at $4{ }^{\circ} \mathrm{C}$, by centrifugation at $3000 \mathrm{~g}$ for $10 \mathrm{~min}$ and then used for the attachment assay.

\subsection{Pharyngeal epithelial cells}

Pharyngeal epithelial cells were collected from a consented normal healthy adult male by scraping the oropharynx with a cotton swab. Cells from the swab were collected in tubes containing $1 / 15 \mathrm{M}$ phosphate buffer (PB, $\mathrm{pH}$ 7.2). Cells were washed three times with $\mathrm{PB}$, by centrifugation at $80 \mathrm{~g}$ for $10 \mathrm{~min}$ at room temperature. Finally, pharyngeal epithelial cells were count with a Burker chamber and adjusted to a density of $5 \times 10^{4}$ cells $/ \mathrm{ml}$.

\subsection{Attachment assay}

The attachment assay was performed as described previously [17] with minor modifications. Bacteria and cells were mixed in equal proportions to a volume of $1 \mathrm{ml}$ and incubated for $30 \mathrm{~min}$ at $37^{\circ} \mathrm{C}$ in a water bath under constant shaking. The Unattached bacteria were then removed by three washings using PBS by centrifugation at $80 \mathrm{~g}$ for $10 \mathrm{~min}$ at room temperature. Finally, the cells were collected on a glass slide by Cytospin (Thermo Shandon International, UK). Smears were Gram-stained and viewed under an oil immersion lens of a light microscope to count the number of attached bacteria on 50 consecutive cells. For each slide counting was done blindly.

\subsection{Treatment of epithelial cells with S-CMC}

For the attachment inhibition assay, pharyngeal epithelial cells were treated with various concentrations of $S$ CMC $(100,10,1,0.1,0.01$ and $0.001 \mu \mathrm{g} / \mathrm{ml})$, and incubated at $37^{\circ} \mathrm{C}$ for $30 \mathrm{~min}$ in a water bath under constant shaking.
Then cells were washed three times with PB at $80 \mathrm{~g}$ for $10 \mathrm{~min}$ at room temperature. Control cells were prepared in a similar manner except they were not treated with $S$-CMC. This was followed by conducting the aforementioned attachment assay.

For the detachment assay the following procedure was performed; after completion of the attachment assay, epithelial cells were treated with various concentrations of $S$-CMC $(100,10,1,0.1,0.01$ and $0.001 \mu \mathrm{g} / \mathrm{ml})$ and incubated at $37^{\circ} \mathrm{C}$ for $30 \mathrm{~min}$ in a water bath under constant shaking. Then cells were washed three times with PBS at $80 \mathrm{~g}$ for $10 \mathrm{~min}$ at room temperature, to remove the detached bacteria. Control cells were prepared in a similar manner except they were not treated with $S$-CMC.

\subsection{Treatment of bacteria with $S$-CMC}

Bacteria at a density of $5 \times 10^{7} \mathrm{cfu} / \mathrm{ml}$ were treated with various concentrations of $S$-CMC $(10,1,0.1,0.01$ and $0.001 \mu \mathrm{g} / \mathrm{ml}$ ) at $37^{\circ} \mathrm{C}$ for $30 \mathrm{~min}$ in a water bath under constant shaking. Then the bacteria were washed three times in PBS at $4{ }^{\circ} \mathrm{C}$ by centrifugation at $3000 \mathrm{rpm}$, each time for $10 \mathrm{~min}$. Bacteria treated similarly but without any drug represented the control sample. Attachment assay was performed as described above and compared with the control. After treatment with $S$-CMC, the viability of $S$. pneumoniae was determined by quantitative cultures on BHI agar containing 7\% defibrinated rabbit blood. The following day, the viability of bacteria was compared with that of the control.

\subsection{Statistical analysis}

All data were expressed as mean $\pm \mathrm{SD}$. Differences between groups were examined for statistical significance using Students $t$-test. Data were considered statistically significant if the $P$ value was lower than 0.05 .

\section{Acknowledgements}

Part of this project was support by Bilkent University Research Fund (MBG-01-04) and by Kyorin Pharmaceutical Co. Ltd., Tokyo, Japan.

\section{References}

[1] Kontiokari T, Uhari M, Koskela M. Antiadhesive effects of xylitol on otopathogenic bacteria. J Antimicrob Chemother 1998;41: 563-5.

[2] Riise GC, Qvarfordt I, Larsson S, Eliasson V, Andersson BA. Inhibitory effect of $\mathrm{N}$-acetylcysteine on adherence of Streptococcus pneumoniae and Haemophilus influenzae to human oropharyngeal epithelial cells in vitro. Respiration 2000;67:552-8. 
[3] Noguchi Y. Effects of carbocysteine on the prevention of chronic respiratory infection. Jpn Med Consultant New Remedies 1989;26: 1608-13. in Japanese.

[4] Zheng CH, Ahmed K, Rikitomi N, Martinez G, Nagatake T. The effects of $S$-carboxymethylcysteine and $N$-acetylcysteine on the adherence of Moraxella catarrhalis to human pharyngeal epithelial cells. Microbiol Immunol 1999;43:107-13.

[5] Ndour CD, Ahmed K, Nakagawa T, Nakano Y, Ichinose A, Tarhan G, Aikawa M, Nagatake T. Modulating effects of mucoregulating drugs on the attachment of Haemophilus influenzae. Microb Pathog 2001; 30:121-7.

[6] Moore RA, Commin SD, Bates G, Phillips CJ. S-carboxymethylcysteine in the treatment of glue ear: quantitative systematic review. BMC Fam Pract 2001;2:3.

[7] Brown DT. Carbocysteine. Drug Intell Clin Pharm 1988;22:603-8.

[8] Watson L, Wilson BJ, Waugh N. Pneumococcal polysaccharide vaccine: a systematic review of clinical effectiveness in adults. Vaccine 2002;20:2166-73.

[9] Ahmed K, Martinez G, Wilson S, Yoshida R, Dhar R, Mokaddas E, Kohno S, Rotimi VO, Nagatake T. The prevalence and clonal diversity of penicillin resistant Streptococcus pneumoniae in Kuwait. Epidemiol Infect 2000;125:573-81.

[10] Cundell DR, Pearce BJ, Sandros J, Naughton AM, Masure HR. Peptide permeases from Streptococcus pneumoniae affect adherence to eucaryotic cells. Infect Immun 1995;63:2493-8.
[11] Watson DA, Musher DM. Interruption of capsule production in Streptococcus pneumoniae serotype 3 by insertion of transposon Tn916. Infect Immun 1990;58:3135-8.

[12] Adamou JE, Wizemann TM, Barren P, Langermann S. Adherence of Streptococcus pneumoniae to human bronchial epithelial cells (BEAS-2B). Infect Immun 1998;66:820-2.

[13] Gosink KK, Mann ER, Guglielmo C, Tuomanen EI, Masure HR. Role of novel choline binding proteins in virulence of Streptococcus pneumoniae. Infect Immun 2000;68:5690-5.

[14] Yother J, White JM. Novel surface attachment mechanism of the Streptococcus pneumoniae protein PspA. J Bacteriol 1994;176: 2976-85.

[15] Dagan R, Givon-Lavi N, Zamir O, Sikuler-Cohen M, Guy L, Janco J, Yagupsky P, Fraser D. Reduction of nasopharyngeal carriage of Streptococcus pneumoniae after administration of a 9-valent pneumococcus conjugate vaccine to toddlers attending day care centers. J Infect Dis 2002;185:927-36.

[16] Ahmed K, Wilson S, Jamal WY, Martinez G, Oishi K, Nagatake T, Rotimi VO. Causative bacteria of respiratory tract infections in Kuwait by quantitative culture of sputum. J Infect Chemother 1999;5: 217-9.

[17] Mbaki N, Rikitomi N, Akiyama M, Matsumoto K. In vitro adherence of Streptococcus pneumoniae to oropharyngeal cells: enhanced activity and colonization of the upper respiratory tract in patients with recurrent respiratory infections. Tohoku J Exp Med 1989;157: $345-54$. 